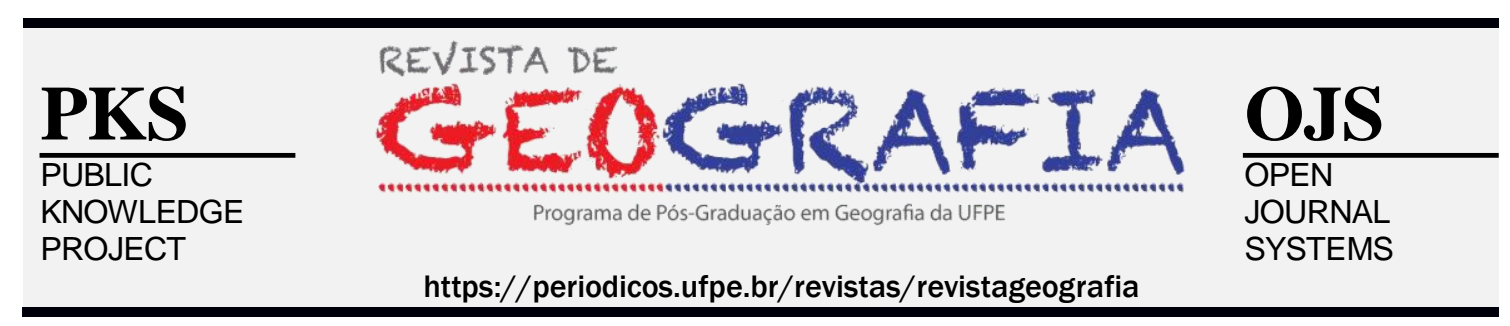

\title{
MAPA DE ANÁLISE CLIMÁTICA DE CIDADES DE PEQUENO E MÉDIO PORTES NO CONTEXTO DO PANTANAL MATO-GROSSENSE
}

\author{
João Carlos Machado Sanches ${ }^{1}$, Renata Mansuelo Alves Domingos ${ }^{2}$, Ana Carolina \\ Vicentim Batista Ribeiro ${ }^{3}$, Gisele Carignani ${ }^{4}$
}

\author{
${ }^{1}$ Universidade do Estado de Mato Grosso.E-mail: sanches@unemat-net.br \\ ${ }^{2}$ Universidade Federal de Santa Catarina.E-mail: mansuelo.alves@gmail.com \\ ${ }^{3}$ Universidade do Estado de Mato Grosso. E-mail: anacarolinavicentim@gmail.com \\ ${ }^{4}$ Universidade do Estado de Mato Grosso.E-mail: carignani@hotmail.com
}

Artigo recebido em 27/05/2019 e aceito em 11/03/2020

\begin{abstract}
RESUMO
As cidades brasileiras crescem com pouco ou nenhum planejamento urbano, e quando o mesmo está presente, geralmente as questões relativas ao clima não são consideradas, principalmente em cidades de pequeno e médio porte. Diante disso, é proposta a elaboração do Mapa de Análise Climática de Cáceres, Mato Grosso, que passou pela reformulação de seu Plano Diretor recentemente. Para tal, foram estudadas as alterações climáticas ao longo dos anos e a influência do espaço construído nos microclimas urbanos da cidade, com dados meteorológicos oficias e transectos móveis. A metodologia utilizada se mostrou adequada, demonstrando que a temperatura e velocidade média dos ventos vêm aumentando ao longo dos anos e, a umidade relativa do ar, diminuindo. Possibilitou ainda a identificação das áreas mais comprometidas da cidade com relação ao clima, bem como as áreas verdes e reservas a serem preservadas. Dessa forma, foi possível traçar diretrizes gerais, que visam à mitigação dos efeitos nocivos identificados, como a criação de parques, arborização viária e controle de adensamento em áreas específicas.
\end{abstract}

Palavras-chave: Planejamento urbano; microclimas urbanos; alterações climáticas.

\section{MAP OF CLIMATE ANALYSIS OF SMALL AND MEDIUM-SIZED CITIES IN THE CONTEXT OF THE MATO-GROSSENSE PANTANAL}

\begin{abstract}
Brazilian cities grow with little or no urban planning, and when it is present, climate issues are generally not considered, especially in small and medium-sized cities. Given this, it is proposed to prepare the Map of Climate Analysis of Caceres, Mato Grosso, which has recently been reformulated its Master Plan. To this end, climate change was studied over the years and the influence of the built space in the urban microclimates of the city, with official weather data and mobile transects. The methodology used was adequate, showing that the average temperature and wind speed have been increasing over the years and the relative humidity has been decreasing. It also enabled the identification of the most compromised areas of the city in relation to the climate, as well as the green areas and reserves to be preserved. Thus, it was possible to draw up general guidelines aimed at mitigating the identified harmful effects, such as the creation of parks, road afforestation and density control in specific areas.
\end{abstract}

Keywords: Urban planning; urban microclimates; climate change. 


\section{INTRODUÇÃO}

Com o crescimento descontrolado dos aglomerados urbanos, que ocorreu principalmente a partir da metade do século XX no Brasil, a relação homem e natureza vem se tornando cada vez mais complexa. A ação humana vem produzindo impactos sobre o meio ambiente natural, ocasionando uma baixa qualidade de vida, relacionadas às alterações dos climas locais.

Assis (2005) afirma que em âmbito local e mesoclimático, o ambiente construído deve ser estudado em detalhe, uma vez que tende a alterar significativamente o clima natural. Já Grimmond et al. (2010) demonstra que as mudanças climáticas ocorrem devido ao processo de urbanização. As mudanças climáticas no ambiente urbano causam efeitos adversos na saúde humana, devido ao desconforto térmico, causado pelo aumento da temperatura e diminuição da umidade relativa do ar, que muitas vezes formam ilhas de calor e produzem uma má distribuição dos ventos. (ASSIS, 2011 \& LAMBERTS et al, 2009).

Em 10 de julho de 2001, foi aprovada a Lei 10.257, chamada Estatuto da Cidade e, segundo ela, os estudos urbanísticos e os aspectos ambientais para qualidade urbana devem contribuir na elaboração dos Planos Diretores. Sendo assim, há a necessidade de produção de conhecimento climático que possa subsidiar tal processo, abrangendo ferramentas e informações de fácil acesso e assimilação para os atores envolvidos com o planejamento urbano.

Nesse contexto, o município de Cáceres, estado de Mato Grosso, passa atualmente pela revisão de seu Plano Diretor, numa realidade de fragilidade ambiental. Trata-se de uma cidade polo, que possui uma forte interligação com o bioma Pantanal, às margens do Rio Paraguai, caracterizado por cerrados sem alagamento periódico, campos inundáveis e ambientes aquáticos, como lagoas de água doce, rios e vazantes. Foi fundado em 1778, durante a expansão Oeste do Brasil colônia e está situado no ponto de confluência entre o rio Paraguai e as rodovias BR-070, BR-174 e BR-364. A partir da década de 1960, com a abertura dessas rodovias e da construção da ponte Marechal Rondon sobre o Rio Paraguai, a cidade passa por intenso crescimento populacional, sem o adequado planejamento.

Atualmente, conta com população estimada de 94.376 pessoas (IBGE, 2019), e seu perímetro urbano engloba quase a totalidade das áreas urbanizadas mas, observa-se que a ocupação desse perímetro é bastante difusa, com grande quantidade de vazios urbanos e baixa densidade populacional. Prevalece os serviços como principal atividade econômica no meio urbano e a pecuária no meio rural. 
Cáceres pertence à subunidade II - A na classificação climática proposta pelo zoneamento socioeconômico-ecológico de Mato Grosso (Maitelli, 2005). Corresponde às depressões e planícies com altitudes entre 95 e 200m, onde o clima pode ser classificado como tropical megatérmico sub-úmido. Nessa subunidade, observa-se uma nítida diminuição dos totais de chuvas. Já as temperaturas médias anuais oscilam entre $25^{\circ} \mathrm{C}$ e $26^{\circ} \mathrm{C}$, enquanto as máximas ultrapassam, frequentemente, $35^{\circ} \mathrm{C}$ durante quase todo o ano, e o período seco se prolonga de abril-maio a setembro-outubro, em geral.

Dessa forma, este estudo visa identificar as alterações climáticas presentes em Cáceres-MT, dentro do processo de revisão do Plano Diretor Municipal. Pretende ainda, através do Mapa de Análise Climática, proporcionar elementos que possibilitem o debate de propostas para o planejamento urbano, numa perspectiva de mitigação dos efeitos nocivos das alterações climáticas observadas.

\section{METODOLOGIA}

A primeira fase desta pesquisa trata da análise dos dados, a partir das informações obtidas pela estação automática do INMET - Instituto Nacional de Meteorologia, instalada na cidade de Cáceres, de modo a verificar a evolução da temperatura, umidade relativa do ar, precipitação, velocidade e direção do evento entre os anos de 1972 e 2017. Essa estação encontra-se instalada nas dependências do $2^{\circ}$ Batalhão de Fronteira do Exército, próximo ao centro histórico tombado pelo IPHAN, e do Rio Paraguai e sua reserva legal, portanto, sem grandes alterações em seu entorno nas últimas décadas.

Os dados obtidos pela estação foram armazenados em planilhas eletrônicas do Microsoft Excel, para geração de gráficos e linhas de tendências. Para análise da direção do vento da cidade de Cáceres, os dados foram armazenados em planilhas eletrônicas do Microsoft Excel, posteriormente tratados no software WRPLOT. Desse modo, é possível obter o vetor resultante de direção predominante dos ventos e sua velocidade média, nos períodos de chuva e de seca na região.

A segunda etapa da pesquisa fundamenta-se na metodologia proposta por SANCHES (2015) para analisar as variáveis climáticas como temperatura e umidade relativa do ar. Trata-se da formulação do Mapa de Análise Climática, elaborado a partir de informações registradas em transectos móveis urbanos e de informações sobre uso e ocupação do solo urbano.

Os pontos de medição do transecto são definidos a partir do grau de impacto das estruturas urbanas na formação dos microclimas urbanos (informações sobre o uso e 
ocupação do solo). A Figura 1 mostra os 15 pontos selecionados, dentro da área urbana consolidada de Cáceres, passando por vias de intenso tráfego e por áreas verdes, representando diversos padrões de uso e ocupação do solo, como comércios, residências e áreas mistas.

As medições foram realizadas no período de estiagem em três horários distintos, as 08, 14 e 20 horas, representando os períodos após o nascer do sol, o mais aquecido e o período após o pôr do sol. A pesquisa ocorreu em três dias consecutivos, sendo quarta-feira, quinta-feira e sexta-feira, no mês de setembro de 2017, período com maiores registros de temperatura do ar na região.

Uma vez que o presente estudo visava contribuir com as discussões do Plano Diretor municipal, o período de coletas de dados se estendeu por apenas quatro meses, não sendo possível verificar as condições no período das chuvas. De qualquer forma, as experiências registradas por SANCHES et al. (2017) e SANCHES (2015) na cidade de Sinop-MT, indicam claramente que as medições no período seco são suficientes para fornecer um panorama das áreas mais afetadas na cidade do ponto de vista climático.

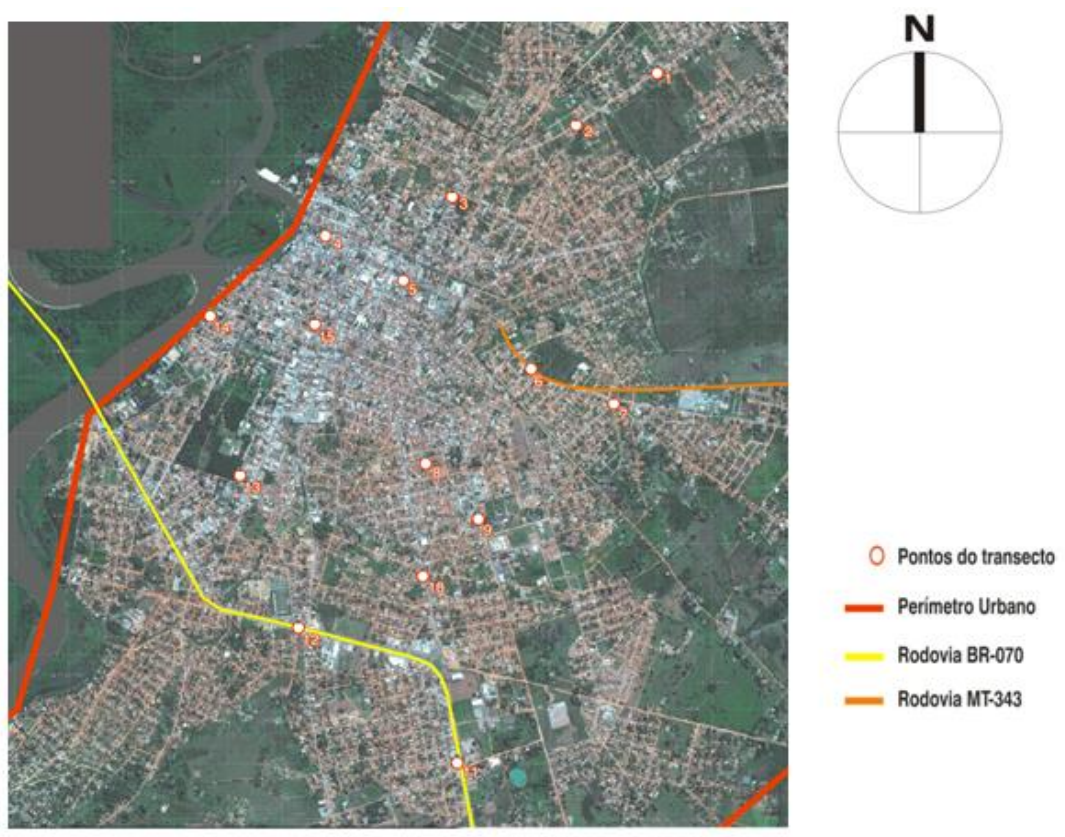

Figura 1- Imagem da cidade de Cáceres mostrando a localização dos pontos de medição da pesquisa.

Os equipamentos utilizados foram um console, que no período de medição fica no interior do veículo, onde é possível visualizar os dados meteorológicos da estação, e um conjunto integrado de sensores, modelo ITWH-1080 da marca Instrutemp, com precisão para temperatura de $\pm 1^{\circ} \mathrm{C}$, faixa de medição de $-40^{\circ} \mathrm{C}$ a $65^{\circ} \mathrm{C}$ e precisão para umidade de $\pm 5 \%$, 
faixa de medição de $10 \%$ a 99\%. O sensor temperatura/umidade é montado dentro de uma proteção contra radiação solar, a fim de minimizar impacto nas leituras. Esse conjunto é acoplado no teto do automóvel através de um suporte metálico.

As medições iniciam-se nos horários definidos anteriormente, a uma velocidade de $40 \mathrm{~km} / \mathrm{h}$, permanecendo pelo menos dois minutos em cada ponto de medição, observando o sinal de recebimento de dados que aparece no console da estação móvel localizada no interior do carro (SANCHES et al., 2017; SANCHES, 2015). Os dados de temperatura e umidade são anotados no minuto exato da medição, para que a posterior correção dos dados seja válida.

Para realizar a correção dos dados da medição móvel, verifica-se o horário no qual um ponto móvel foi registrado e soma-se ou diminui-se a diferença de valor de umidade relativa ou temperatura do ar registrada na estação fixa (INMET), com relação ao valor no início da medição (SANCHES et al., 2017).

A partir do tratamento dos dados, são obtidos os gráficos de variação média e os mapas de distribuição de temperatura e umidade nos períodos matutino, vespertino e noturno, a partir do software de geoestatística SAGA GIS. Esses dados possibilitam a criação do Mapa de Análise Climática, a partir da sobreposição dos mapas de distribuição citados, com o mapa de estruturas urbanas, sem diferenciação de peso entre os mapas produzidos.

\section{RESULTADOS}

Análise dos dados a partir das informações obtidos pela estação automática do INMET

Os dados obtidos pela estação automática do INMET, instalada na cidade de Cáceres, indicou a média mensal da temperatura, entre os anos de 1972 - 2017. Observou-se as menores temperaturas nos meses de junho e julho (cerca de $23^{\circ} \mathrm{C}$ ), devido às frentes frias atuantes nesse período. Já as maiores temperaturas média são registradas nos meses de outubro e novembro, início do período chuvoso. A maior temperatura média mensal registrada pelo INMET foi no mês de outubro com $27,4^{\circ} \mathrm{C}$, e a menor no mês de julho com $22,5^{\circ} \mathrm{C}$.

Também foi analisada a temperatura média anual dos anos de 1972 a 2017, Figura 2. Percebe-se que há uma tendência do aumento da temperatura anual, em cerca de $1,5^{\circ} \mathrm{C}$, justificada pelo aumento das áreas impermeáveis, aumento da densidade populacional e aumento do fluxo de veículos automotores nesse período. Além disso, observou-se que nos 
anos de 2001 e 2012 a temperatura anual média foram maiores que $27^{\circ} \mathrm{C}$, ultrapassando os domínios da subunidade em que Cáceres se insere.

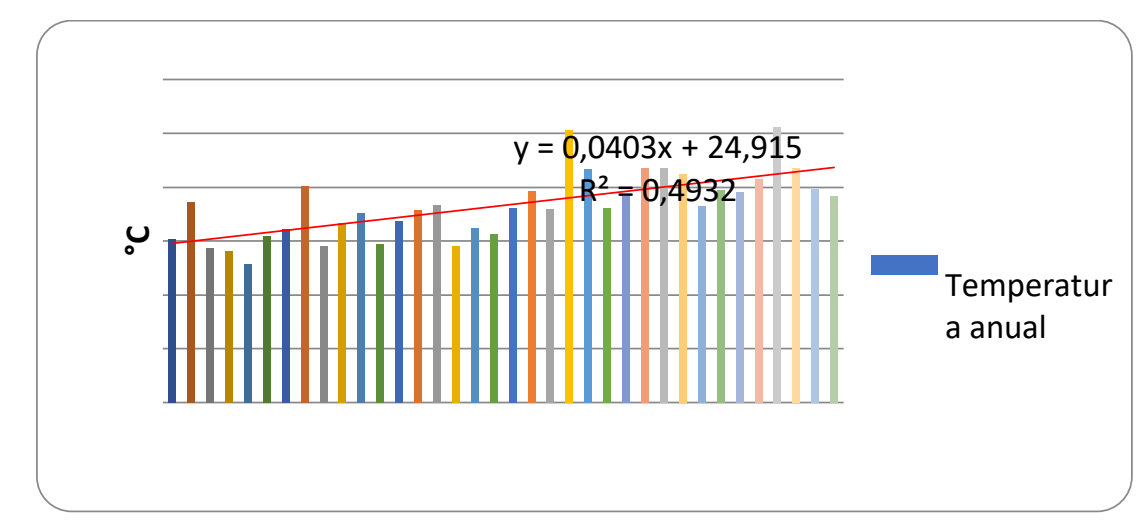

Figura 2 - Temperatura anual média entre os anos de 1972- 2017, através de dados obtidos pelo INMET.

Para a caracterização da umidade relativa do ar, foi feita a média mensal das temperaturas nos anos registrados. As maiores umidades relativas do ar médias foram registradas nos meses de janeiro a março, auge da estação chuvosa, com $82 \%$, as menores no mês de agosto com $64 \%$.

Observa-se uma linha de tendência decrescente na umidade anual média, Figura 3, uma vez que há diminuição de áreas verdes e aumento do escoamento superficial da água, contribuindo para a diminuição da umidade relativa do ar no decorrer dos anos. Trata-se de uma diminuição acentuada, variando de cerca $80 \%$ para cerca de $71 \%$ nesses 44 anos avaliados.

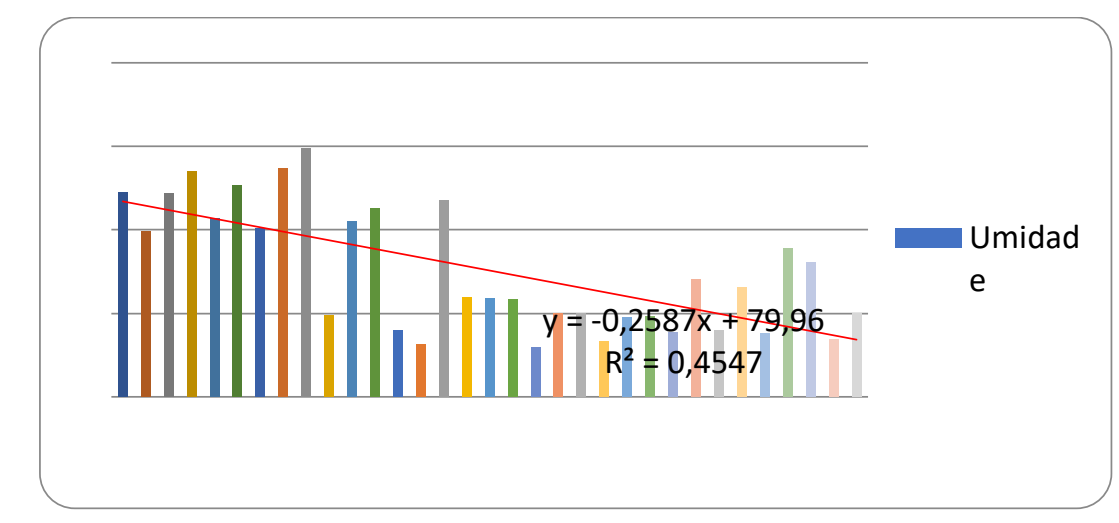

Figura 3 - Umidade média anual relativa do ar nos anos de 1972 a 2017, dados obtidos pelo INMET.

Outra variável analisada foi a precipitação média mensal, entre os anos de 1972 e 2017. Verificou-se uma baixa precipitação nos meses de junho, julho e agosto, com 
19,22mm, 15,12mm e 15,88mm, respectivamente. As maiores precipitações no período estudado ocorreram nos meses de janeiro e dezembro, com uma precipitação média mensal de $239,49 \mathrm{~mm}$ e $206,10 \mathrm{~mm}$.

Já para a precipitação média anual, Figura 4, a maior precipitação foi registrada no ano de 1972 com 151,23mm e a menor em 1981 com 68,53mm. Obteve-se uma precipitação média de aproximadamente $104 \mathrm{~mm}$ em todo período já registrado em Cáceres, sem a verificação de nenhuma tendência de aumento ou diminuição dessa variável ao longo dos anos.

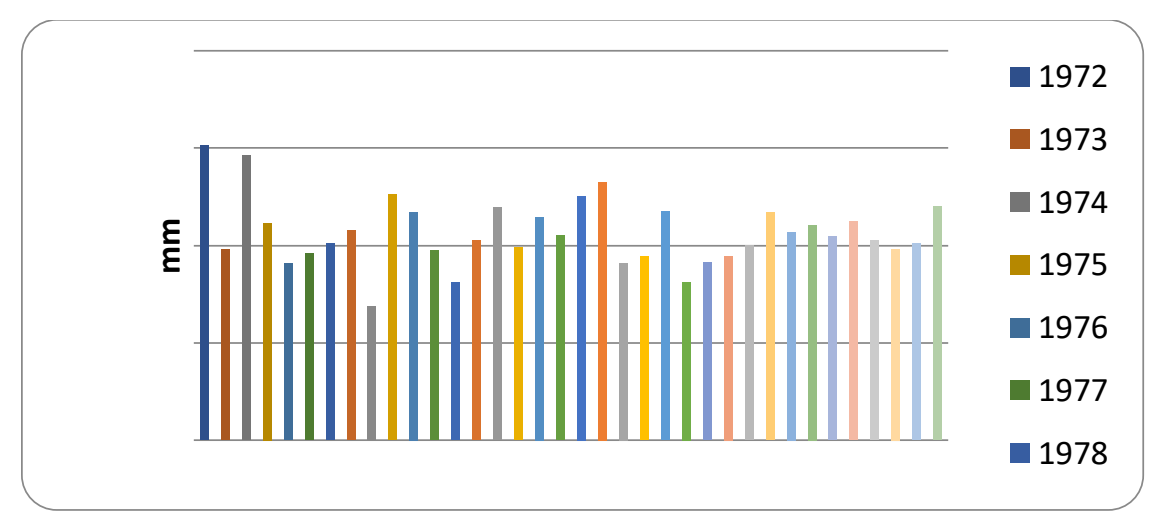

Figura 4 - Precipitação média anual relativa do ar nos anos de 1972 a 2017, dados obtidos pelo INMET.

Ao analisar a velocidade do vento entre os anos de 1972 e 2017 foi possível registrar os meses de fevereiro e março com velocidades de $1,01 \mathrm{~m} / \mathrm{s}$ e $0,98 \mathrm{~m} / \mathrm{s}$, respectivamente, sendo essas as menores velocidades médias obtidas dentre os meses. O mês de setembro se destaca por ter a maior velocidade dos ventos no período estudado, com uma velocidade média de $1,40 \mathrm{~m} / \mathrm{s}$.

$\mathrm{Na}$ velocidade média anual, Figura 5, observa-se uma linha de tendência crescente, passando de cerca de $0,8 \mathrm{~m} / \mathrm{s}$ em 1972, para aproximadamente $1,6 \mathrm{~m} / \mathrm{s}$ em 2017 , decorrente do desmatamento ocasionado pela expansão horizontal da cidade e da ocupação agropecuária de seu entorno. Logo, o vento tende a atingir a cidade com velocidade maior, sem encontrar barreiras vegetais. A velocidade média do vento em Cáceres em todo período estudado é de $1,17 \mathrm{~m} / \mathrm{s}$. 


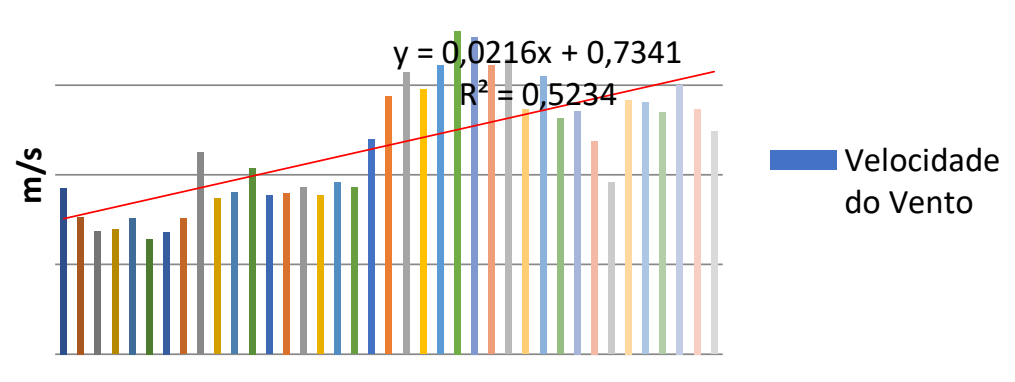

Figura 5 - Velocidade média relativa do ar nos anos de 1972 a 2017, dados obtidos pelo INMET.

Para a caracterização dos ventos, foi gerada a Rosa dos Ventos a partir do WRPlot, utilizando todos dados disponibilizados pelo INMET. Observou-se, em média, que a direção predominante dos ventos predominantes é Norte Nordeste (NNE) com uma velocidade média de $1,35 \mathrm{~m} / \mathrm{s}$, conforme representa a Figura 6 . Portanto, além da baixa velocidade registrada, os ventos atingem a cidade paralelamente ao Rio Paraguai, ou seja, sem carregar a umidade proveniente do rio.

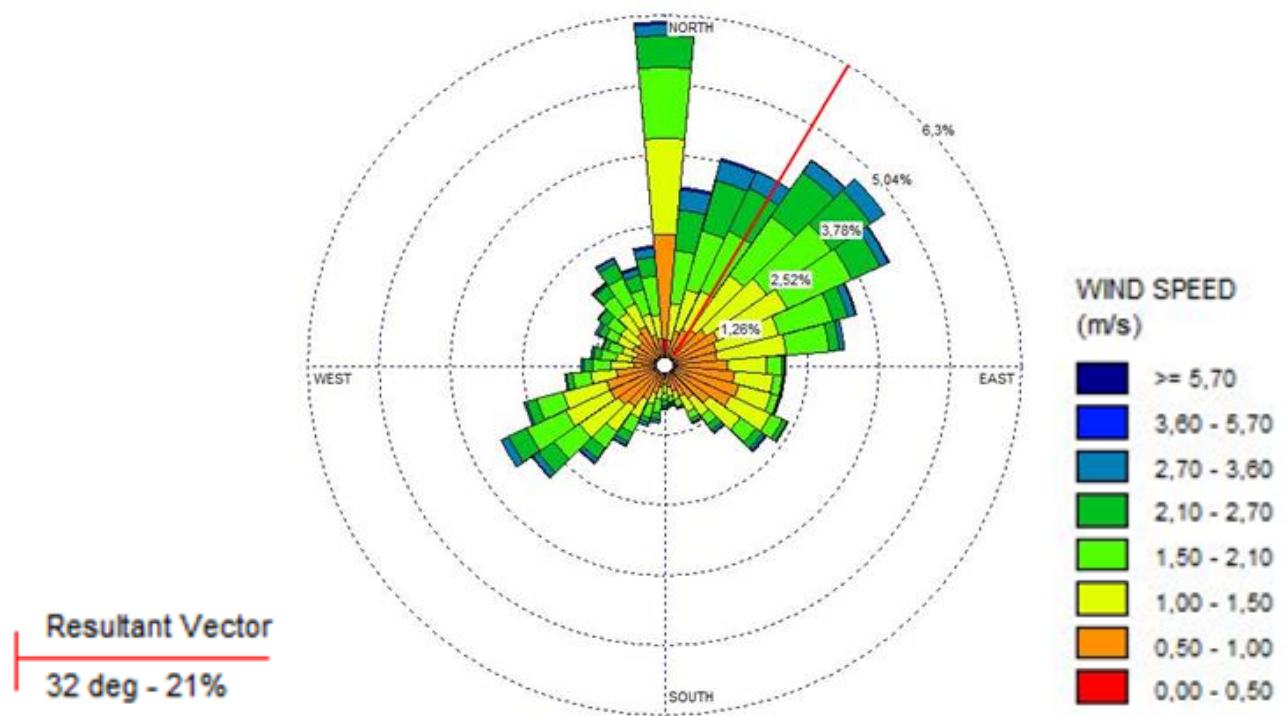

Figura 6 - Rosa dos ventos todo período. Fonte: Software WRPLOT.

Medições a partir dos pontos do transecto móvel

Período Matutino

Na média, o ponto 9, localizado na Av. Getúlio Vargas, apresentou a maior temperatura com $26,6^{\circ} \mathrm{C}$, enquanto que no ponto 14 , localizado próximo ao Rio Paraguai, apresentou o menor valor de temperatura nesse período de medições com $25,8^{\circ} \mathrm{C}$. 
Percebe-se a influência do uso e ocupação do solo na temperatura, visto que o ponto 9 é caracterizado pela máxima temperatura média no período da manhã, e se localiza em uma região de intenso fluxo de veículos e pessoas, além de possuir uma alta densidade construtiva, com hospital, residências e comércios. Já o ponto considerado com menor temperatura (ponto 14), se encontra ao lado do Rio Paraguai e próximo à reserva vegetal militar, demonstrando assim, a influência dos corpos d'água e da vegetação na diminuição da temperatura na cidade.

Já a maior diferença de temperatura foi entre o ponto 9 e 15 registrada no dia 30/08/2017 com uma variação $1,2^{\circ} \mathrm{C}$, sendo considerada significativa para o período matutino, uma vez que a cidade está iniciando o processo de absorção de radiação.

$\mathrm{Na}$ caracterização da umidade relativa do ar, no período matutino na cidade de Cáceres, notou-se um comportamento inverso ao da temperatura, já que no ponto 9 registrouse, na média, um menor valor de umidade relativa, de 64\%. Já a umidade relativa máxima foi obtida no ponto 14, ao lado do Rio Paraguai, com $69 \%$, o que também coincide com a menor temperatura pela manhã.

Para esse período de medições, a maior diferença de umidade relativa entre os pontos foi registrada no dia 30/08/2017, com uma variação de $10 \%$, sendo que a maior umidade registrada nesse dia se encontra no ponto 14 (59\%) e a menor no ponto 11 (49\%). Os pontos 14 e 15, localizados próximos ao Rio Paraguai, registraram as maiores umidades relativas do ar, entretanto, fica claro que esse recurso hídrico influencia na umidificação apenas nos pontos próximos a ele. Como visto anteriormente, a direção predominante dos ventos não favorece a dispersão da umidade do rio pela cidade.

Através da observação dos mapas de distribuição de temperatura e umidade relativa do ar do período matutino (Figuras 7 e 8), pode-se constatar uma região com maiores temperaturas na parte central da cidade de Cáceres, englobando a Avenida 7 de setembro e Praça Barão, localizada no centro histórico, que estão representadas pelos pontos 4 e 5, respectivamente. Quanto à umidade, registrou-se nesses mesmos pontos uma baixa umidade do ar, uma vez que são áreas com grande densidade construtiva e o solo completamente impermeabilizado e predominantemente comercial, além de possuir intenso fluxo de veículos e pedestres. 


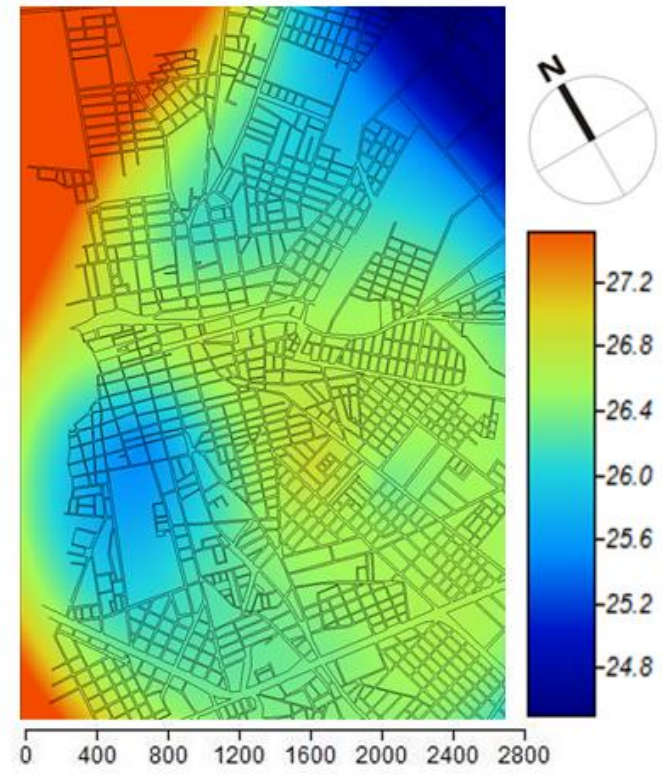

Figura 7 - Mapa de distribuição da temperatura do ar no período matutino.

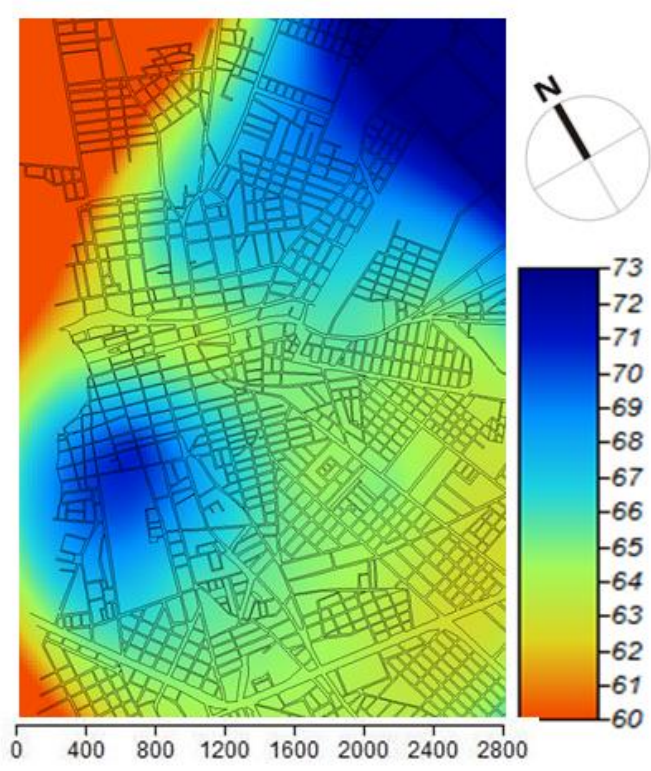

Figura 8 - Mapa de distribuição da umidade relativa do ar no período matutino.

\section{Período Vespertino}

As medições desse período registraram médias máximas em diferentes pontos da medição do período anterior, já que a cidade passa pela absorção máxima da radiação solar. Logo, a temperatura média máxima registrada se encontra no ponto $5\left(37,2^{\circ} \mathrm{C}\right)$, localizado na Av. 7 de setembro, na parte central da cidade. Esse aumento na temperatura pode ser justificado devido ao intenso fluxo de veículos automotores e pedestres nessa região, por ser uma área predominantemente comercial, além da presença de escolas e hospitais próximos.

Já os pontos 14 e 15, localizados próximo ao Rio Paraguai, registraram a menor temperatura média de $35,8^{\circ} \mathrm{C}$, demonstrando assim a influência dos recursos hídricos na temperatura. No dia 30/08/2017 observou-se a maior variação de temperatura entre os pontos de temperatura média máxima (ponto $5,39,6^{\circ} \mathrm{C}$ ) e temperatura média mínima (ponto 15 , $37,8^{\circ} \mathrm{C}$ ), sendo essa diferença de $1,9^{\circ} \mathrm{C}$.

Para as medições de umidade nesse período, o comportamento inverso à temperatura permaneceu, caracterizando assim, uma menor umidade relativa no ponto de maior temperatura. Nesse caso, o ponto 6 registrou, na média, a menor umidade relativa do ar com $28 \%$, não sendo o ponto de menor temperatura. Entretanto se encontra próximo ao ponto de menor temperatura, ponto 5 com $29 \%$ e possuem uso e ocupação do solo semelhantes. Já o ponto de maior umidade relativa do ar permaneceu no ponto 15 (35\%), devido à presença do Rio Paraguai nessa região. 
A maior diferença de umidade relativa, entre os pontos, encontrada nesse período de medições, foi no dia 01/09/2017, com 9\% de variação entre o ponto com maior umidade relativa registrada (35\%) e menor umidade relativa (26\%), sendo esses coincidentes com a menor e a maior temperatura registrada nesse período, respectivamente.

Os mapas de distribuição da temperatura e umidade relativa do ar, para o período vespertino (Figura 9 e 10), mostram que as regiões com menor temperatura e maior umidade relativa do ar se encontram em áreas próximas ao Rio Paraguai, obtendo assim influência desse recurso nos pontos próximos a ele. Nota-se ainda que é uma área predominantemente residencial, com alguns comércios, que também sofre influência da vegetação presente na reserva militar.

Nos pontos com máxima temperatura média e menor umidade relativa do ar (pontos 5 e 6), observa-se uma área predominantemente comercial, com intenso fluxo de veículos e pedestres, pois se encontram em uma área com hospital e escolas próximos. Possui baixa presença de vegetação próxima, sendo as vias completamente impermeáveis, contribuindo para o aumento da temperatura nessa região.

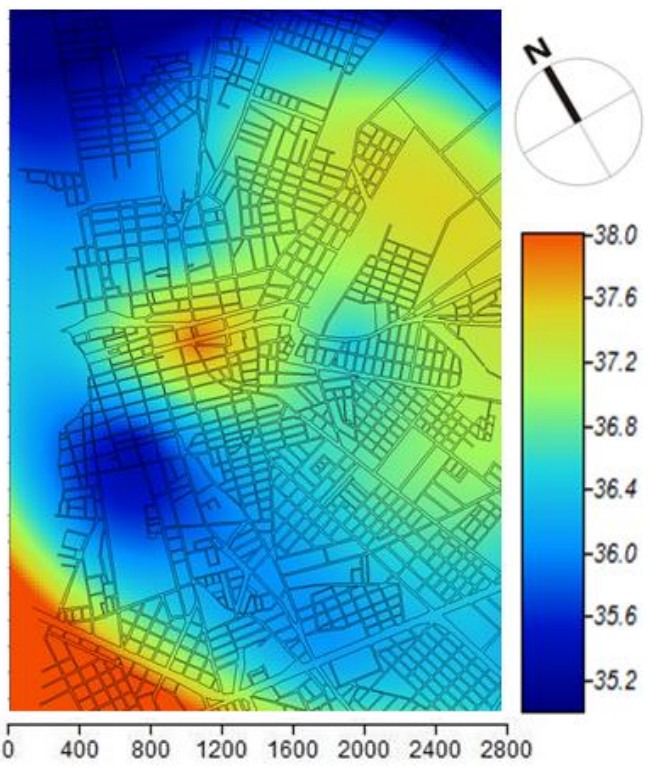

Figura 9 - Mapa de distribuição da temperatura do ar no período vespertino.

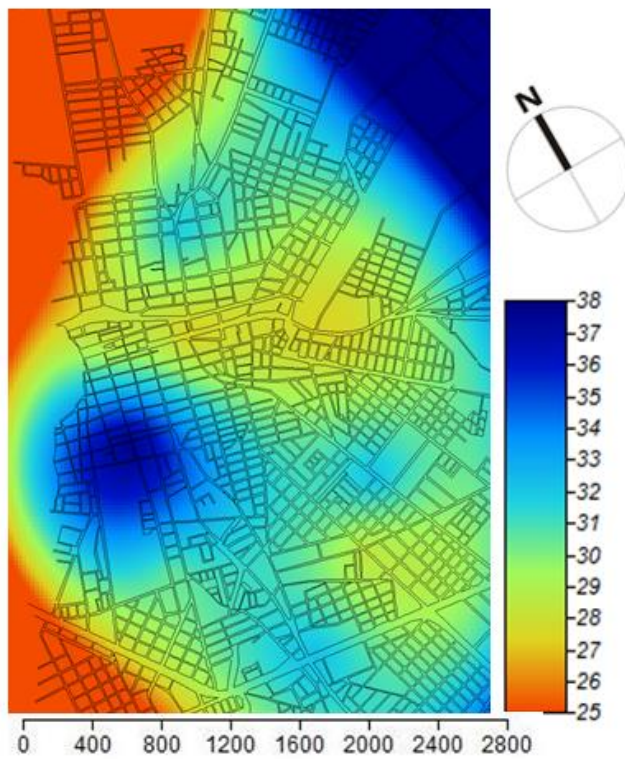

Figura 10 - Mapa de distribuição da umidade relativa do ar no período vespertino. 
Período Noturno

No período noturno, registrou-se, em média, que os pontos 2 e 3, localizados na Av. São João, apresentaram os menores registros de temperatura com $30,1^{\circ} \mathrm{C}$, enquanto que o ponto 5, localizado na Av. 7 de Setembro, continuou apresentando a maior temperatura registrada, com $31,1^{\circ} \mathrm{C}$.

A máxima variação encontrada nesse período de medição, foi no dia 01/09/2017 em que o ponto 5 apresentou a maior temperatura de $31,4 \%$ e os pontos 2 e 3 apresentaram a menor temperatura de $29,5^{\circ} \mathrm{C}$, registrando uma variação de $1,9^{\circ} \mathrm{C}$.

Em relação às medições realizadas para umidade relativa do ar, observou-se, em média, que a umidade máxima permaneceu no ponto 15, próximo ao Rio Paraguai, com 52\%, coincidindo com a menor temperatura registrada. Já mínima umidade relativa encontrou-se no ponto 5, localizado na Av. 7 de Setembro, com $48 \%$.

No dia 01/09/2017 verificou-se a maior variação da umidade relativa do ar entre os pontos 5 e 15 . Com $46 \%$ e $57 \%$ respectivamente, uma variação de $9 \%$ de umidade relativa dentro da cidade de Cáceres.

Os mapas de distribuição da temperatura e umidade relativa do ar, para o período noturno (Figura 11 e 12), demonstram que a região com maiores registros de temperatura se encontra na parte central da cidade, áreas predominantemente comerciais, com escolas e hospital próximos, contribuindo para a intensificação do fluxo de veículos automotores e pedestres, elevando assim a temperatura e, consequentemente, baixando a umidade relativa do ar.

Nesses dias de medições, a temperatura média mínima foi registrada em pontos diferentes dos outros períodos analisados. Tratam-se dos pontos 2 e 3, localizados na Av. São João, próximos a Universidade do Estado de Mato Grosso (UNEMAT), uma área predominantemente residencial, com alguns comércios próximos. Não possui pavimentação asfáltica, contribuindo para a rápida dissipação de calor. Já a máxima umidade relativa registrada coincidiu com os outros períodos, tornando o ponto 15, próximo ao Rio Paraguai, a região mais úmida. 


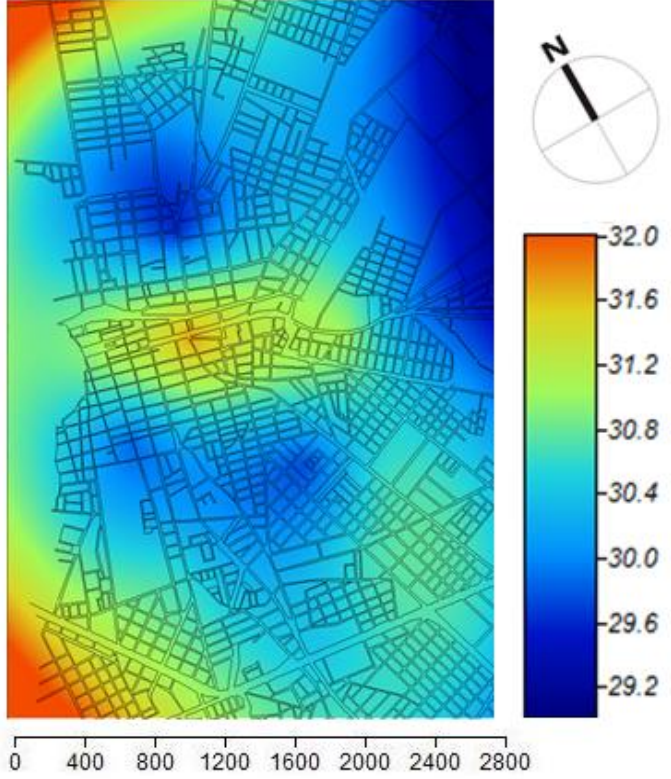

Figura 11 - Mapa de distribuição da temperatura do ar no período noturno.

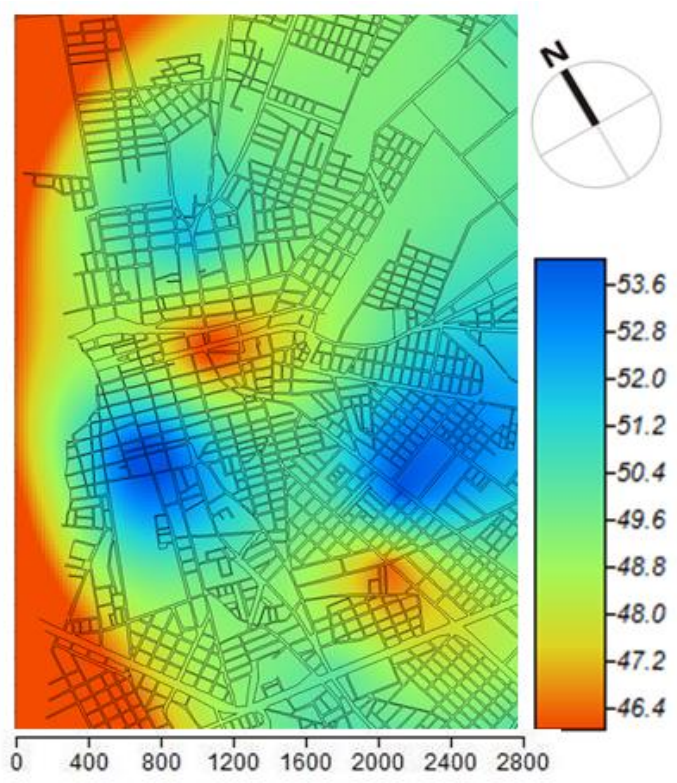

Figura 12 - Mapa de distribuição da umidade relativa do ar no período noturno.

\section{Mapa de Análise Climática}

O mapa mostrado na Figura 13 indica as regiões da cidade mais e menos comprometidas com relação ao clima urbano. Ele é elaborado em função da sobreposição dos mapas de distribuição de temperatura e umidade relativa e a partir do conhecimento do regime dos ventos, expostos anteriormente.

Observa-se que uma região mais comprometida, em vermelho e laranja (Zonas 1 e 2), onde as alterações climáticas são máximas, com intenso aumento dos valores de temperatura e diminuição dos valores de umidade relativa do ar, além de registrar os menores valores de velocidade do ar. Concentra-se, principalmente, no centro da cidade, da Praça Barão até a Avenida 7 de Setembro, englobando uma área de concentração comercial e de serviços, e de intenso tráfego de veículos e pessoas.

Há uma tendência de expansão dessas alterações pelos eixos formados pelas Avenidas Talhamares e Getúlio Vargas, em função da intensa atividade urbana verificada ali, mas, também, em função da influência dos ventos dominantes. Esses ventos, vindos da direção Nordeste, tendem a espalhar essa área mais comprometida na direção Sul da cidade.

Por outro lado, as áreas em verde claro e verde escuro (Zonas 6 e 7) apresentam as condições climáticas mais próximas às naturais. Engloba as reservas de vegetação e as áreas de preservação permanente ao longo dos cursos d'água. Engloba ainda as áreas desflorestadas próximas às áreas urbanizadas, com baixa ou nenhuma ocupação. São áreas fundamentais na 
regulação do clima local e importantes na produção de ventos frescos e úmidos durante todo o ano.

A partir do Mapa de Análise Climática, é possível traçar diretrizes para a elaboração de propostas de intervenções de modo a mitigar os efeitos nocivos registrados. Indica-se, por exemplo, a adoção de medidas de limitação de veículos automotores e a implantação de áreas verdes e de arborização viária na região central da cidade (Zonas 1 e 2). Já nas regiões ainda vegetadas e sem ocupação (Zonas 6 e 7), é importante que se adotem medidas que garantem a preservação das áreas verdes com vegetação de grande porte e de restrição de ocupação das demais áreas.

Vale ressaltar a baixa densidade identificada na cidade, assim como a existência de muitos lotes desocupados nas áreas urbanizadas. Isso indica que deve ser priorizada a ocupação dessas áreas, em detrimento das aberturas de novos loteamentos, notadamente na porção Norte e Nordeste da cidade, direção dos ventos predominantes, como mostrado anteriormente.

Todas essas constatações foram levadas aos debates com a população e a equipe técnica da prefeitura, resultando em propostas e diretrizes incluídas nos capítulos do projeto de Lei do Plano Diretor Municipal.

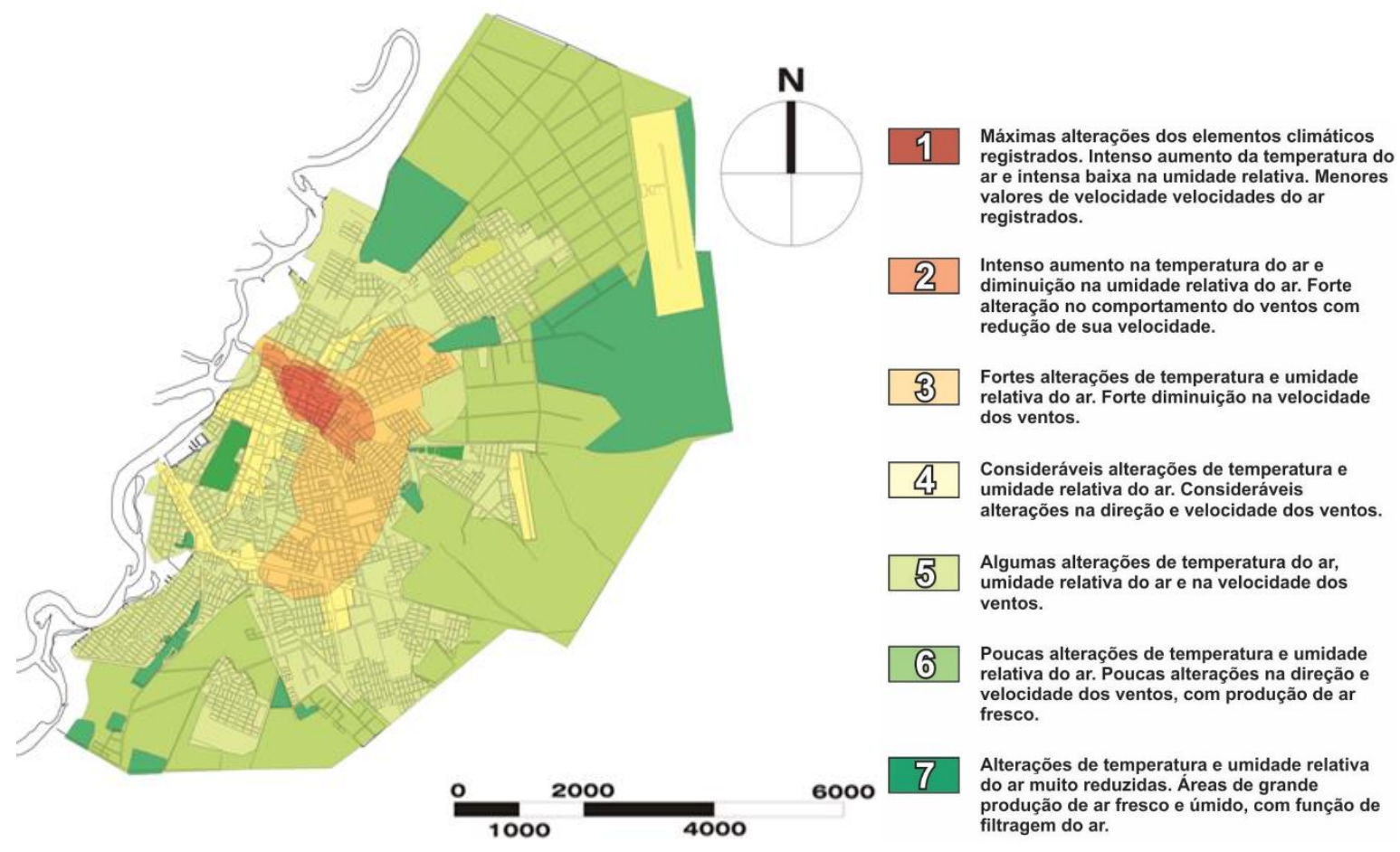

Figura 13 - Mapa de Análise Climática de Cáceres. 


\section{CONCLUSÃO}

Com base na pesquisa realizada, foi possível analisar as variáveis climáticas como temperatura, umidade relativa do ar, precipitação, velocidade e direção do vento do município de Cáceres-MT, de forma a estabeler um paralelo com as condições de evolução da área urbanizada e de seu entorno. Esses dados mostram que, com os passar dos ano, houve o aumento da temperatura média anual e diminuição da umidade relativa do ar, devido ao aumento das áreas impermeáveis, da densidade construtiva, do fluxo de veículos automotores e da diminuição das áreas verdes.

A partir do mapa de análise climática do município, observa-se as regiões mais comprometidas com relação ao clima urbano, diretamente relacionadas com o uso e ocupação do solo, concentrando as maiores temperaturas e menores umidade relativas nas áreas mais consolidadas, localizadas no centro da cidade. Esse mapa evidencia a necessidade de adoção de diretrizes que busquem mitigar os efeitos nocivos identificados, servindo como ferramenta que possibilita discutir essas medidas com todos os atores envolvidos na revisão do Plano Diretor, já em curso.

Dessa forma, nota-se que a metologia utilizada, desenvolvida por Sanches (2015), se mostrou apropriada para contribuir com a incorporação do clima no processo de planejamento urbano em cidades de pequeno e médio porte, notadamente na região do pantanal matogrossense, assim como já havia sido registrado para a cidade de Sinop-MT na Amazônia Legal mato-grossense.

\section{REFERÊNCIAS}

ASSIS, E. S. A abordagem do clima urbano e aplicações no planejamento da cidade: reflexões sobre uma trajetória. VIII Encontro Nacional sobre Conforto no Ambiente Construído, Anais... p. 92-101, 2005.

ASSIS, E. S. Estudo de ilha de calor em áreas urbanas e sua contribuição ao planejamento: o caso de Belo Horizonte, MG. Mudanças climáticas e o impacto das cidades, v.4, n.1, 2011.

GRIMMOND, S. Climate of cities. In: Atmospheric observation panel for climate. Sixteenth session. Geneva. 2010. 
Revista de Geografia (Recife) V. 37, Nº. 1, 2020

IBGE. Instituto Brasileiro de Geografia e Estatística (2019). Disponivel em: <https://www.ibge.gov.br/cidades-e-estados/mt/caceres.html> Acesso em: 26 de novembro de 2019.

LAMBERTS, R., GOMES, P., GOMES P. S. O estudo do clima urbano e legislação urbanística: considerações a partir do caso Montes Claros - MG. Ambiente Construído, v. 9, n. 1, p. 73-91, 2009.

MAITELLI, G. T. Interações atmosfera-superfície. In: Moreno, G, Higa, T. C. S. (Org.). Geografia de Mato Grosso: Território, sociedade, ambiente. Cuiabá: Entrelinhas, 2005. cap. 13, p. 238-249.

SANCHES, J. C. M., CANDIDO, C. R., OHIRA, S. Clima urbano como critério de planejamento de assentamentos de habitações de interesse social: o caso de Sinop-MT, na Amazônia Legal brasileira. 4o CIHEL - Congresso Internacional da Habitação no Espaço Lusófono, Anais... 2017.

SANCHES, J. C. M. Uma metodologia para a inserção do clima como critério para o planejamento urbano: análise da cidade de Sinop-MT. Tese (Doutorado em Urbanismo)

- Universidade Federal do Rio de Janeiro, Rio de Janeiro. 